\title{
INVESTIGATION ON PHYSICAL AND MECHANICAL PROPERTIES OF BANANA AND PALMYRA FIBER REINFORCED EPOXY COMPOSITES
}

\author{
VENNAPUSA Vijaya Bhaskar1*, KOLLA Srinivas², DEVIREDDY Siva Bhaskara Rao ${ }^{3}$ \\ ${ }^{I}$ Research Scholar, Department of Mechanical Engineering, Acharya Nagarjuna University \\ College of Engineering and Technology, Guntur 522510, Andhra Pradesh, India, \\ e-mail: vennapusavijayabhaskar@gmail.com \\ ${ }^{2}$ Department of Mechanical Engineering, RVR \& JC College of Engineering, Guntur 520109, \\ Andhra Pradesh, India \\ ${ }^{3}$ Department of Mechanical Engineering, St. Ann's College of Engineering \\ and Technology, Chirala, Andhra Pradesh, 523187, India
}

\begin{abstract}
The present work addresses the physical and mechanical properties of banana and palmyra fiber reinforced epoxy composites with the aim of study on the effect of weight ratio and fiber percentage. The banana and palmyra fibers were arranged with different weight ratios (1:1, 1:3, and 3:1) and then mixed with the epoxy matrix by hand lay-up technique to prepare the hybrid composites with various fiber percentages $(10 \%, 20 \%$, $30 \%$ and $40 \%$ ). The properties are measured by testing its density, water absorption, tensile strength, impact strength, hardness and flexural strength and compared. From the results, it was indicated that addition of banana and palmyra fiber in to the matrix material up to $30 \%$ by fiber percentage results in increasing the mechanical properties and slightly variation with weight ratios. Interfacial analysis of the hybrid composites were also observed by using scanning electron microscope (SEM) to study the internal failures and micro structure of the tested specimen.
\end{abstract}

KEYWORDS: Hybrid composites, Mechanical properties, Natural fibers, Scanning Electron Microscope, Water absorption.

\section{Introduction}

For the past decade, scientists and researchers are using the natural fibers as a reinforcement material in the area of polymer composites. Natural fiber reinforced composites are used in several applications such as automotive parts, aerospace, structural members and marine structures and these materials which are exposed to different types of loads or forces. So, understand the mechanical performance of polymer composites is very important. Polymer composites reinforced with manmade fibers have good mechanical properties but these materials are not recyclable. Various researchers carried out the research work by using natural fibers as reinforcement in polymer composites [1-2]. Effect of fiber length and weight fraction on water absorption and mechanical properties short snake grass fiber reinforced polyester composites studied by Sathishkumar et al. [3]. The results indicated that by increasing the weight fraction and fiber length the mechanical properties of composites are increased. Alamri and Low [4] investigated the flexural properties, impact strength and fracture toughness of the recycled cellulose fiber reinforced composites. The results revealed that the maximum flexural strength and flexural modulus were attained with a fiber percentage of $46 \mathrm{wt} \%$. Hybrid composite materials contain two or more types of reinforcement phases in a matrix phase. These materials have unique features that can provide strength, stiffness, and ductility, which is difficult to attain with mono polymer composites. 
The effect of the hybridization on mechanical properties of banana and jute fiber reinforced epoxy composites has been studied by several researchers [5-7]. From the results it is observed that the mechanical properties such as tensile strength, flexural strength and impact energy of hybrid composite exhibit the superior properties than the mono composites. Arthanarieswaran et al. [8] assessed the mechanical properties of banana and sisal reinforced polymer composites and found that by adding the glass fiber to the banana and sisal fibers can improve the flexural strength and tensile strength of hybrid composites. Srinivasan et al. [9] investigated the mechanical properties of banana and flax reinforced hybrid composites and the results revealed that the impact and flexural properties of hybrid composite greater than the individual glass fiber composite. Saw et al. [10] investigated the effect of hybridization on water absorption and mechanical properties jute and coir fiber reinforced composites. From the results it is concluded that the hybrid composite showed improved properties compared to individual coir and jute fiber reinforced composites. Lalit et al. [11] studied the various natural fibers reinforced biopolymer composites and concluded that the biopolymers are best sustainable for fabricating the composites. Some studies also performed on the simulation of mechanical behaviour of composites [12].

Presently, the use of banana and palmyra fibers are the agricultural waste materials. By utilizing these materials for making agricultural by-products in the composite industry will enhancement the economy of palmyra and banana agronomy. Most of the previous literature works reported the mechanical properties of the natural fiber reinforced composites by changing its weight fractions, volume fraction of fiber and different length of fibers. In the present work, the banana and palmyra fiber reinforced epoxy composites prepared by varying the fiber weight percentages and weight ratios. The physical and mechanical properties such as density, water absorption, tensile properties, flexural properties, hardness, and impact energy are analyzed. Interfacial analysis of the composites has also been investigated using scanning electron microscope (SEM).

\section{Experimental}

\subsection{Materials}

Banana and palmyra fibers were procured from the local suppliers. The properties of banana and palmyra fiber are shown in Table 1 . The unidirectional banana and palmyra fibers were cut into $30 \mathrm{~cm}$ length and arranged in a layers form as shown in Fig. 1. The epoxy and hardener mixture is used as a matrix for binding the reinforcement layers. Epoxy resin (LY 556) and hardener (HY 951) were supplied by Sree industrial composite products, Hyderabad.

Table 1. Properties of banana and palmyra fiber $[6,13]$

\begin{tabular}{|c|c|c|}
\hline Property & Banana fiber & Palmyra fiber \\
\hline Density $\left(\mathrm{g} / \mathrm{cm}^{3}\right)$ & 1.35 & 1.03 \\
\hline Tensile strength $(\mathrm{MPa})$ & 54 & $97-196$ \\
\hline Tensile modulus $(\mathrm{GPa})$ & 3.48 & $2.5-5.4$ \\
\hline$\%$ elongation & 5.9 & $2-4.5$ \\
\hline Cellulous content $(\%)$ & $63-64$ & 49.6 \\
\hline Hemicelluloses $(\%)$ & 19 & 18 \\
\hline Lignin content $(\%)$ & 5 & 21.2 \\
\hline
\end{tabular}




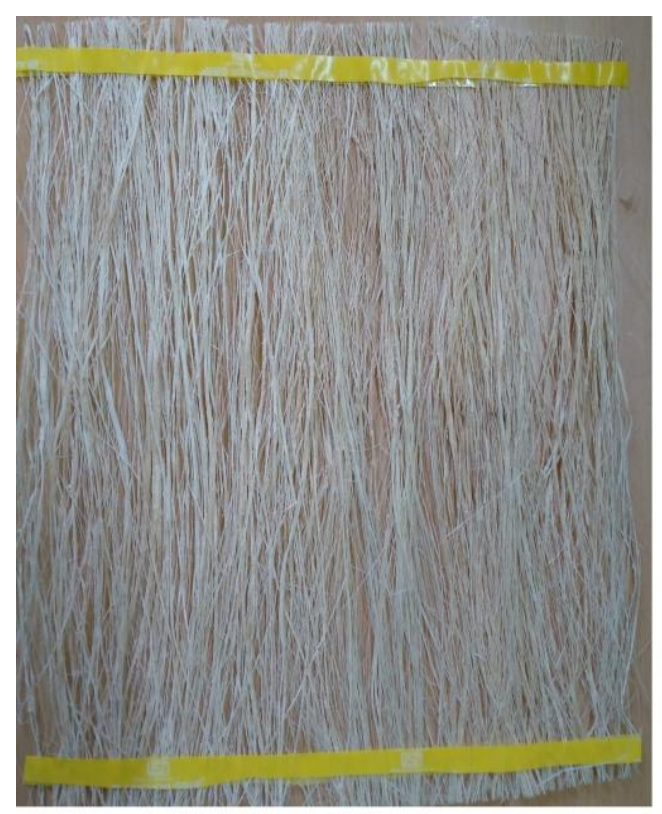

(a)

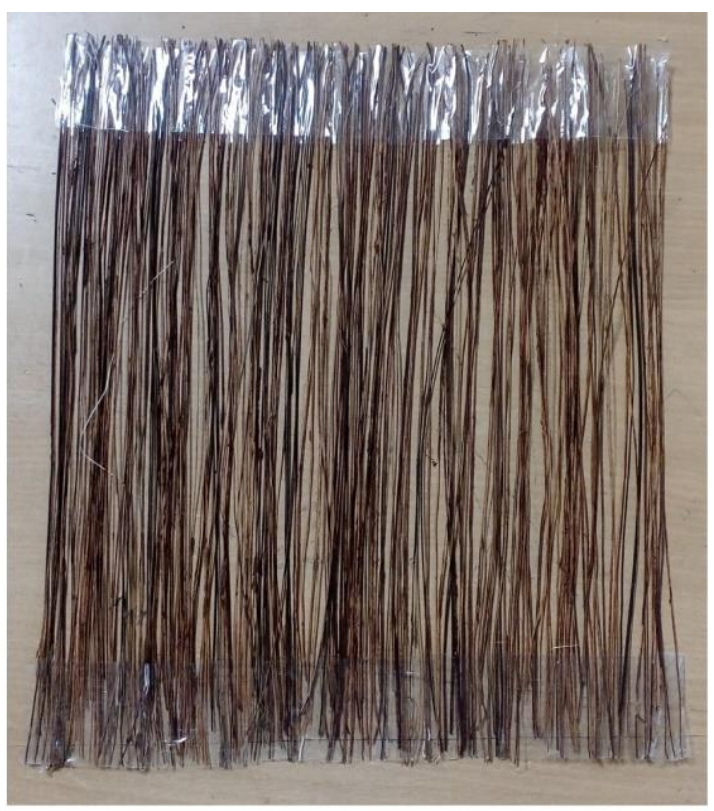

(b)

Fig. 1 Individual layers of (a) Banana fiber and (b) Palmyra fiber

\subsection{Preparation of Hybrid Composite}

The hybrid composites of were manufactured by manual hand lay-up procedure. Initially banana and palmyra fibers are oven dried to remove the moisture content and arranged in layers form. Mold releasing spray is applied on the surfaces of mold sheet to ease removal of the composite laminate after curing. Thirteen groups of composite specimens with total fiber percentage of $0-40 \%$ were fabricated by varying weight ratio of banana and palmyra reinforcement as presented in Table 2. The reinforcement was impregnated with the LY556 epoxy matrix material and HY951 hardener in the ratio of 10:1. Now a pressure of $1.0 \mathrm{MPa}$ is applied for a curing period of $48 \mathrm{~h}$ on the mold for avoiding voids in hybrid composites. After curing, the composite samples removed from the mold, and cut into necessary dimensions of physical and mechanical characterization as per ASTM standards. The hybrid composite specimens for physical and mechanical tests were shown in Fig. 2.

Table 2. Detailed designation and composition of fabricated composites.

\begin{tabular}{|c|c|}
\hline Composites & Composition \\
\hline $\mathrm{C} 1$ & Epoxy (100 wt.\% ) \\
\hline $\mathrm{C} 2$ & Epoxy (90 wt.\% ) + Banana (5 wt.\% ) + Palmyra (5 wt.\% ) \\
\hline $\mathrm{C} 3$ & Epoxy (80 wt.\% ) + Banana (10 wt.\% ) + Palmyra (10 wt.\% ) \\
\hline $\mathrm{C} 4$ & Epoxy (70 wt.\% ) + Banana (15 wt.\% ) + Palmyra (15 wt.\% ) \\
\hline $\mathrm{C} 5$ & Epoxy (60 wt.\% ) + Banana (20 wt.\% ) + Palmyra (20 wt.\% ) \\
\hline C6 & Epoxy (90 wt.\% ) + Banana (2.5 wt.\% ) + Palmyra (7.5 wt.\% ) \\
\hline $\mathrm{C} 7$ & Epoxy (80 wt.\% ) + Banana (5 wt.\% ) + Palmyra (15 wt.\% ) \\
\hline $\mathrm{C} 8$ & Epoxy (70 wt.\% ) + Banana (7.5 wt.\% ) + Palmyra (22.5 wt.\% ) \\
\hline C9 & Epoxy (60 wt.\% ) + Banana (10 wt.\% ) + Palmyra (30 wt.\% ) \\
\hline $\mathrm{C} 10$ & Epoxy (90 wt.\% ) + Banana (7.5 wt.\% ) + Palmyra (2.5 wt.\% ) \\
\hline $\mathrm{C} 11$ & Epoxy (80 wt.\% ) + Banana (15 wt.\% ) + Palmyra (5 wt.\% ) \\
\hline $\mathrm{C} 12$ & Epoxy (70 wt.\% ) + Banana (22.5 wt.\% ) + Palmyra (7.5 wt.\% ) \\
\hline $\mathrm{C} 13$ & Epoxy (60 wt.\% ) + Banana (30 wt.\% ) + Palmyra (10 wt.\% ) \\
\hline
\end{tabular}




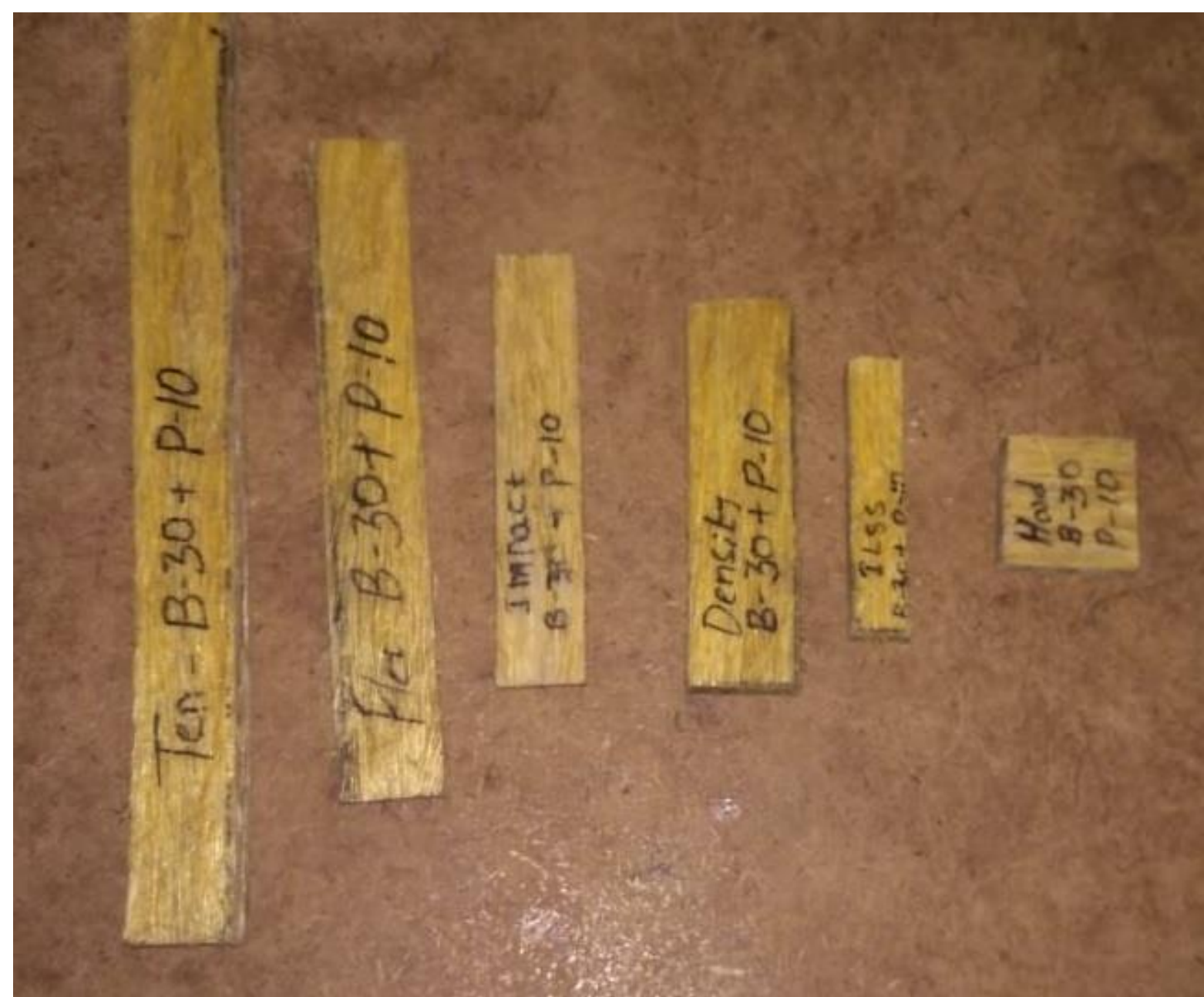

Fig. 2 Fabricated hybrid composite specimens as per ASTM standards

\subsection{Physical Testing of Composites}

Physical properties such as density, void content and water absorption of the composite specimens were calculated based on the ASTM standards. The experimental density $\left(\rho_{\text {ce }}\right)$ of the hybrid composite material can be measured as per ASTM D 792-91 standard by the Archimedes principle. The theoretical density $\left(\rho_{\mathrm{ct}}\right)$ of the hybrid composites can be determine from the following equation.

$$
\rho_{\mathrm{ct}}=\frac{1}{\left(\mathrm{~W}_{\mathrm{fb}} / \rho_{\mathrm{fb}}\right)+\left(\mathrm{W}_{\mathrm{fp}} / \rho_{\mathrm{fp}}\right)+\left(\mathrm{W}_{\mathrm{m}} / \rho_{\mathrm{m}}\right)}
$$

Where, $\mathrm{W}$ and $\rho$ represent the weight fraction and density, respectively. The suffixes $\mathrm{fb}, \mathrm{fp}$, and $\mathrm{m}$ stand for the banana fiber, palmyra fiber, and matrix respectively. The void percentage $(\mathrm{Vv})$ of the composite material is measured from the experimental density and theoretical density as per ASTM D 2734-70 standard using the following equation (2).

$$
\mathrm{V}_{\mathrm{v}}=\frac{\rho_{\mathrm{ct}}-\rho_{\mathrm{ce}}}{\rho_{\mathrm{ct}}}
$$

Water absorption percentage of hybrid composites are observed with different time periods at a room temperature. The initial weight of the composite specimens were measured before immersed in distilled water. The test was conducted as per ASTM D570-98 with sample size is $60 \times 10 \times 4 \mathrm{~mm}$. The composite specimens are taken out from the water for every $24 \mathrm{~h}$ and reweighed. The weight absorption percentage is measured using the following equation. 


$$
\% \mathrm{~W}=\frac{\left(\mathrm{W}_{\mathrm{f}}-\mathrm{W}_{\mathrm{i}}\right)}{\mathrm{W}_{\mathrm{i}}} \times 100
$$

Where, $\mathrm{W}_{\mathrm{f}}$ is the final weight of specimen after immersion time and $\mathrm{W}_{\mathrm{i}}$ is the initial weight of specimen.

\subsection{Mechanical Testing of Hybrid Composites}

Mechanical properties such as tensile strength, flexural strength, impact energy and hardness of the hybrid composites were measured. The tensile strength is measured based on the ASTM standard D3039-76 and the specimen size is $153 \mathrm{~mm} \times 12.7 \mathrm{~mm} \times 4 \mathrm{~mm}$. The universal testing machine Instron 1195 is used to perform the test at a crosshead speed of 10 $\mathrm{mm} / \mathrm{min}$. Flexural strength is measured by conducting three-point bending test based on ASTM D 790 standards. The three-point bending test was carried out on rectangular samples using same universal testing machine Instron 1195 with specimen size is $100 \mathrm{~mm} \times 12.7 \mathrm{~mm}$ $\times 4 \mathrm{~mm}$. The impact energy is calculated by using Charpy impact tester (VEEKAY test lab, Pune, India) according to ASTM D 256. The dimension of the composite specimen is $64 \times$ $\mathrm{mm} 12.7 \times \mathrm{mm} 4 \times \mathrm{mm}$ and the depth of the notch is $2 \mathrm{~mm}$ at $45^{\circ}$ angle on one side at the center. The micro-hardness of the hybrid composite specimens are measured based on the ASTM D785 test standards using Vickers hardness tester. For each test, three samples were tested and the average value is obtained.

\subsection{Interfacial Analysis using Scanning Electron Microscope}

The micro structure and failure modes of the tensile tested hybrid composites are observed by scanning electron microscope JEOL JSM-6480LV. The broken portions of the specimens were cut and mounted on stubs with silver paste for inspection.

\section{Results and Discussion}

\subsection{Density and Void Percentage}

Density and void percentage is one of the important parameter, which will affect the mechanical properties of the hybrid composites. The density values of banana fiber, palmyra fiber and neat epoxy are found to be $1.35 \mathrm{~g} / \mathrm{cm}^{3}, 1.03 \mathrm{~g} / \mathrm{cm}^{3}$, and $1.15 \mathrm{~g} / \mathrm{cm}^{3}$ respectively. The theoretical, experimental densities and void percentage of the fabricated hybrid composites for different weight ratios and fiber percentages is shown in Table 3.

Table 3. Theoretical, experimental densities and void percentage of the composites.

\begin{tabular}{|c|c|c|c|}
\hline Composite & $\begin{array}{c}\text { Theoretical } \\
\text { density }\left(\mathrm{g} / \mathrm{cm}^{3}\right)\end{array}$ & $\begin{array}{c}\text { Experimental } \\
\text { density }\left(\mathrm{g} / \mathrm{cm}^{3}\right)\end{array}$ & $\begin{array}{c}\text { Void } \\
\text { percentage }(\%)\end{array}$ \\
\hline $\mathrm{C} 1$ & 1.150 & 1.146 & 0.347 \\
\hline $\mathrm{C} 2$ & 1.152 & 1.144 & 0.694 \\
\hline $\mathrm{C} 3$ & 1.154 & 1.141 & 1.126 \\
\hline $\mathrm{C} 4$ & 1.156 & 1.138 & 1.557 \\
\hline $\mathrm{C} 5$ & 1.158 & 1.135 & 1.986 \\
\hline $\mathrm{C} 6$ & 1.144 & 1.138 & 0.524 \\
\hline $\mathrm{C} 7$ & 1.139 & 1.127 & 1.053 \\
\hline $\mathrm{C} 8$ & 1.133 & 1.116 & 1.501 \\
\hline $\mathrm{C} 9$ & 1.127 & 1.105 & 1.952 \\
\hline
\end{tabular}




\begin{tabular}{|l|l|l|l|}
\hline $\mathrm{C} 10$ & 1.16 & 1.151 & 0.775 \\
\hline $\mathrm{C} 11$ & 1.169 & 1.155 & 1.197 \\
\hline $\mathrm{C} 12$ & 1.179 & 1.157 & 1.866 \\
\hline $\mathrm{C} 13$ & 1.189 & 1.158 & 2.607 \\
\hline
\end{tabular}

It is clearly observed from the table that the theoretical density values were more than the experimental density values due to voids present during the fabrication of composites. From the Table, it was also depicts that the void percentage increases with the fiber percentage due to poor adhesion between the reinforcement and matrix materials. Another reason may be the natural fibers contain lumens which also act as voids. It is also found that, the hybrid composites with weight ratio of banana and palmyra fiber as 1:3 shows the less void percentage as compared to other two weight ratios.

\subsection{Water Absorption}

The trends of water absorption for $10 \mathrm{wt} . \%, 20 \mathrm{wt} . \%, 30 \mathrm{wt} . \%$ and $40 \mathrm{wt} . \%$ of hybrid composites under different weight ratios are shown in Fig. 3. It can be found that water absorption percentage is increases as fiber percentage increases. The reason behind for increase in water absorption may be due to the micro cracks, presence of voids cellulose fibers have a lumen which permits more water to be absorbed. The water absorption rate in the starting is linear and rapid, after which it slows down and finally becomes stabilize at around $216 \mathrm{hrs}$. At maximum fiber percentage (40 wt.\%), the ultimate water absorption of banana and palmyra fiber reinforced hybrid composites is found $12.14 \%, 11.51 \%$, and $12.61 \%$ with weight ratio of banana and palmyra reinforcement as $1: 1,1: 3$, and $3: 1$ respectively. The composites with higher weight percentage of palmyra have the lowest water absorption percentage. The banana fibers contain higher percentage of cellulose content and many polar hydroxyl bonds which result to high water absorption properties compared to the palmyra fiber. A similar observation on water absorption behaviour of natural fiber reinforced polymer composites was reported by the former researchers [14].

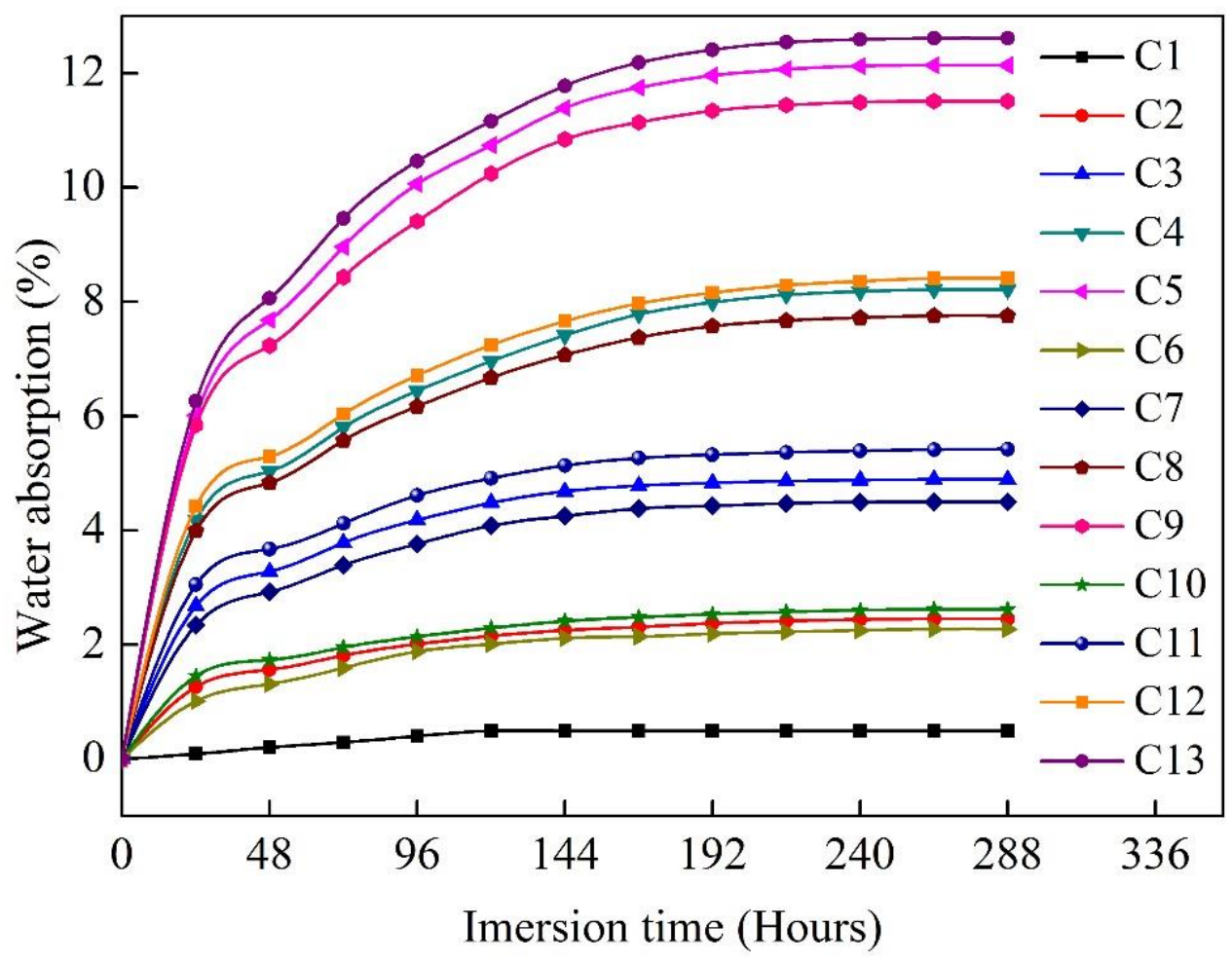

Fig. 3 Water absorption of banana and palmyra reinforced epoxy composites 


\subsection{Tensile Strength and Young's modulus}

The effect of fiber percentage on tensile strength and Young's modulus of banana and palmyra reinforced epoxy composites are shown in Fig. 4 and 5. The tensile strength and Young's modulus of the pure epoxy resin is observed to be $32.28 \mathrm{MPa}$ and $3.32 \mathrm{Gpa}$. It can be understood that the tensile strength of the composite increases with the fiber percentage of banana and palmyra fiber increases up to $30 \mathrm{wt}$. \%. After that there is a decrease in the tensile strength of the hybrid composites at $40 \mathrm{wt} \%$ of fiber percentage. The maximum tensile strength of banana and palmyra composites with weight ratios of 1:1, 1:3 and 3:1 are in the range of $60.82 \mathrm{MPa}, 64.75 \mathrm{MPa}$ and $49.32 \mathrm{MPa}$ respectively.

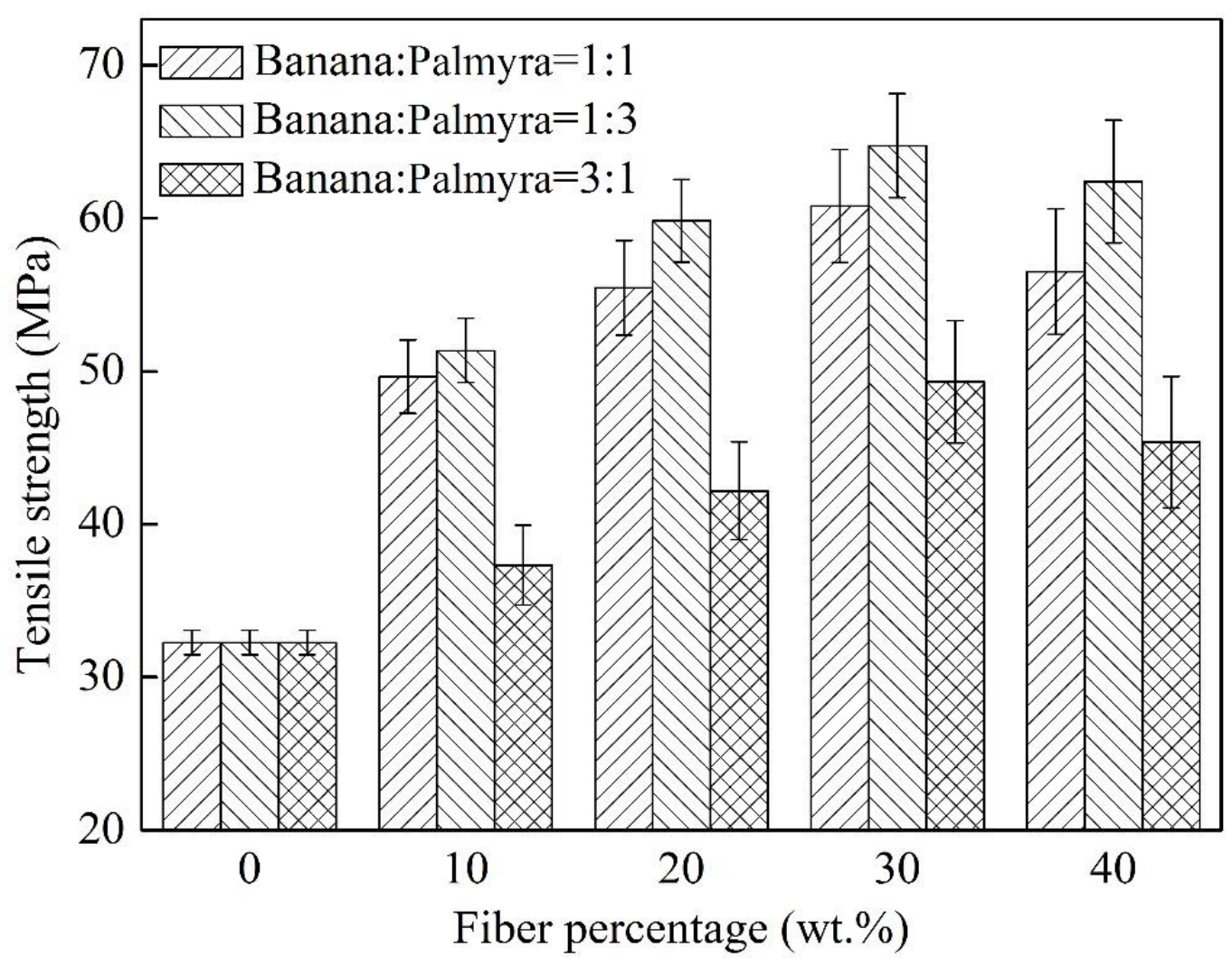

Fig. 4 Tensile strength comparison of different hybrid composite materials 


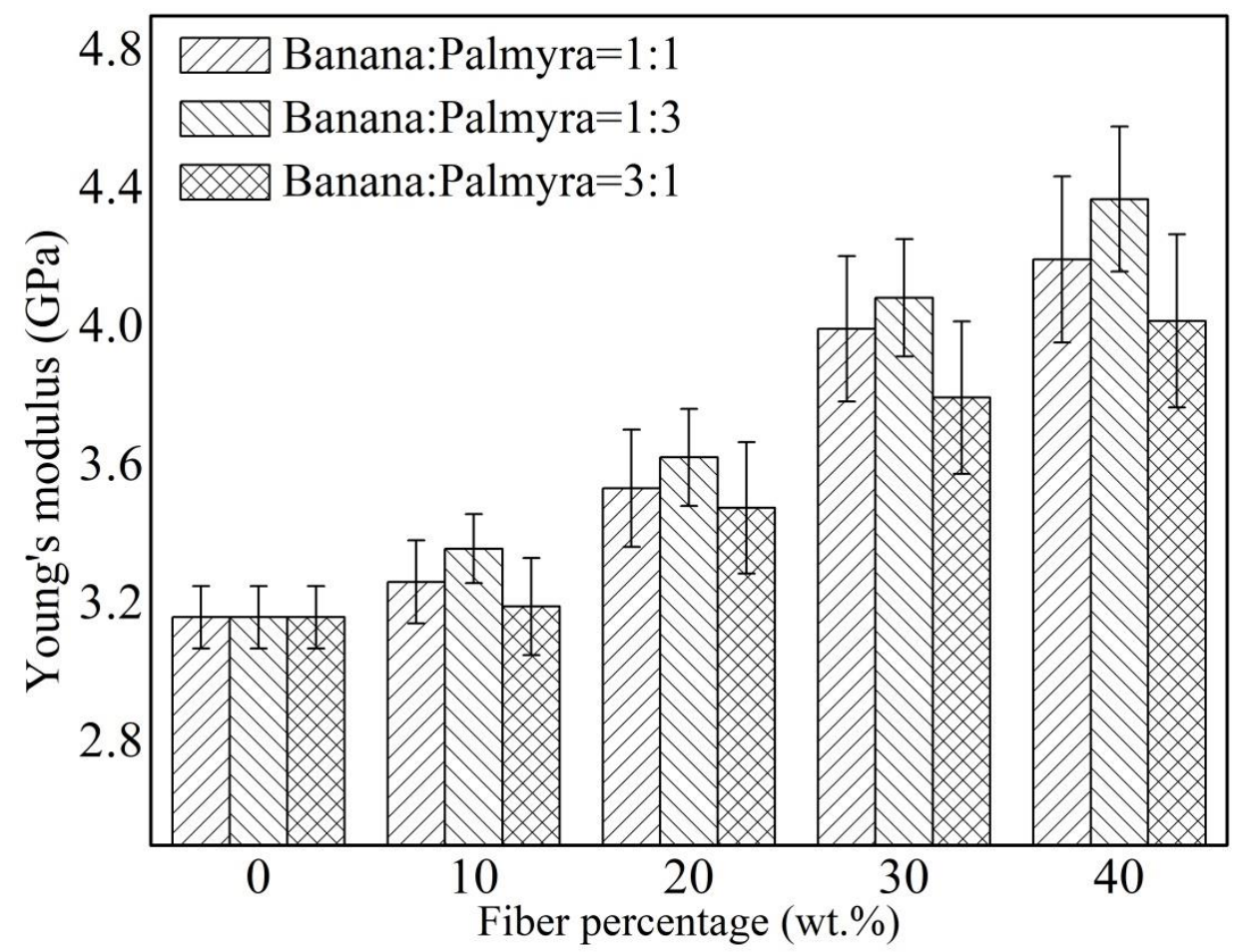

Fig. 5 Tensile modulus comparison of different hybrid composite materials

The Young's modulus of the hybrid composite increases up to $40 \mathrm{wt}$. \% of fiber percentage and the values are identified as $4.19 \mathrm{GPa}, 4.37 \mathrm{GPa}$, and $4.07 \mathrm{GPa}$ with weight ratio of banana and palmyra fiber as 1:1, 1:3, and 3:1, respectively. The percentage improvement from neat epoxy to $40 \mathrm{wt}$. $\%$ of fiber percentage in 1:1, 1:3, and 3:1 weight ratio of hybrid composites are found to be $26.2 \%, 30 \%$ and $22.5 \%$, respectively. The results indicated that the composite with weight ratio of banana and palmyra as 1:3 gives enhanced tensile strength than the other two types of weight ratios considered. The lower tensile strength at 40 wt. \% of hybrid composites may be due to the epoxy matrix was not sufficient to dissolve in to the reinforcement and fiber agglomeration that results to decrease stress transfer between the reinforcement and matrix [15].

\subsection{Flexural Strength and Modulus}

The variation in flexural strength and modulus as a function of fiber percentage and weight ratio for banana and palmyra fiber reinforced hybrid composites is shown in Fig. 6 and 7 . From Figure, it is clearly found that for all the weight ratios of 1:1, 1:3 and 3:1, the flexural strength and modulus is significantly increases with increase in fiber percentage up to 30 wt. \%, after this, the flexural properties start to decrease while increasing the fiber percentage. The reason behind in decrease the flexural strength with increasing fiber percentage may be due to the reinforcement to reinforcement contact increases and deterioration of reinforcement and epoxy matrix adhesion. The maximum flexural strength of hybrid composites with weight ratio of banana and palmyra fiber as $1: 1,1: 3$, and $3: 1$ are $92.83 \mathrm{MPa}, 101.39 \mathrm{MPa}$, and 81.71 $\mathrm{MPa}$, respectively at $30 \mathrm{wt}$ \% of fiber percentage. At $30 \mathrm{wt} . \%$ fiber content, the hybrid composite improves the flexural strength by $101 \%, 120 \%$ and $77 \%$ over the pure epoxy with weight ratio of banana and palmyra reinforcement as $1: 1,1: 3$, and 3:1, respectively. 


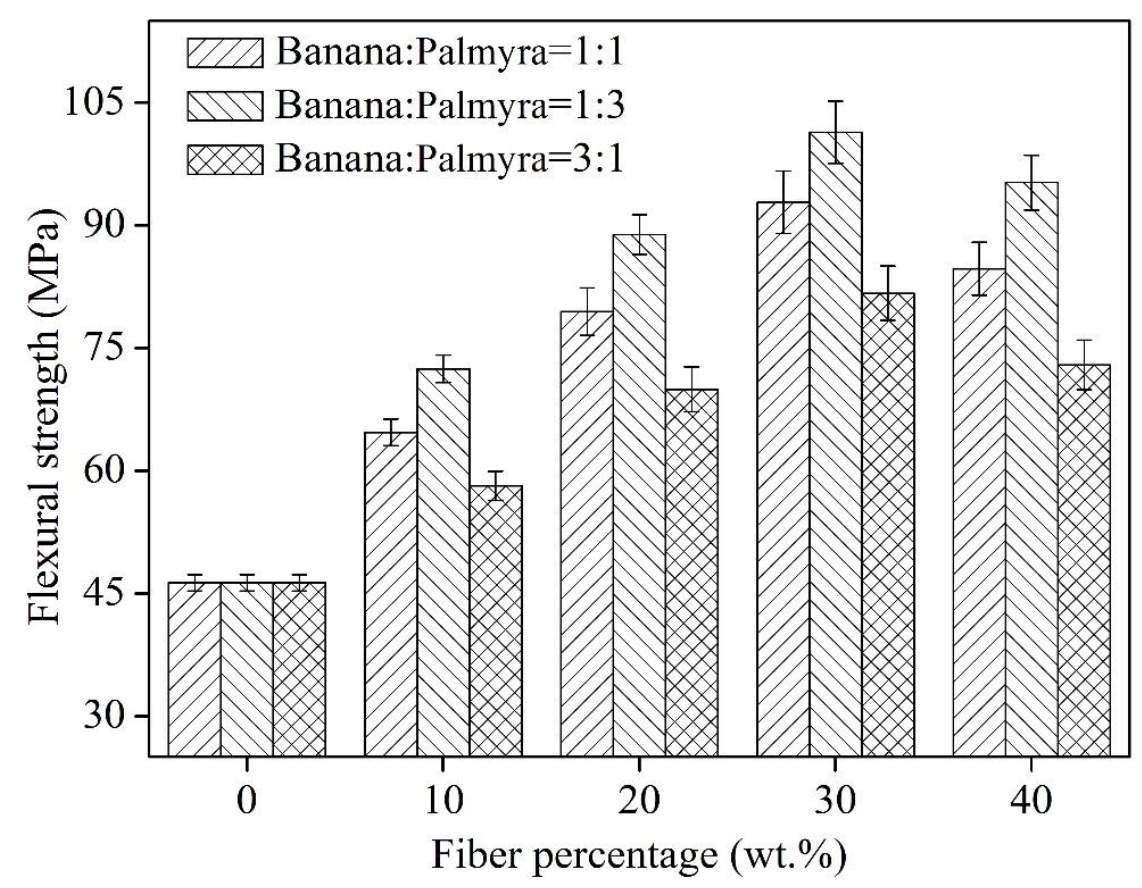

Fig. 6 Flexural strength comparison of different hybrid composite materials

At 30 wt. $\%$ of fiber percentage, the flexural modulus increases to $6.98 \mathrm{GPa}, 7.34 \mathrm{GPa}$, and $6.21 \mathrm{GPa}$ with weight ratio of banana and palmyra fiber as $1: 1,1: 3$, and $3: 1$, respectively. The percentage improvement from neat epoxy to $30 \mathrm{wt}$. $\%$ of fiber percentage in 1:1, 1:3, and 3:1 weight ratio of hybrid composites are found $110 \%, 121 \%$ and $87 \%$, respectively. A similar type of observation was reported by Yusoff et al. [16] in oil palm fiber reinforced epoxy composites. The reason behind the flexural properties to be higher than tensile properties due to the composite material is subjected to the flexural loading; the extreme fibers are subjected to the maximum stress. If the outer fibers are free from voids and defects, the flexural properties will be controlled by the strength of those outer fibers. In case of tensile loading all the fibers in the composite are subjected to the same stress and failure will occur when the weakest fiber reaches its limiting tensile stress.

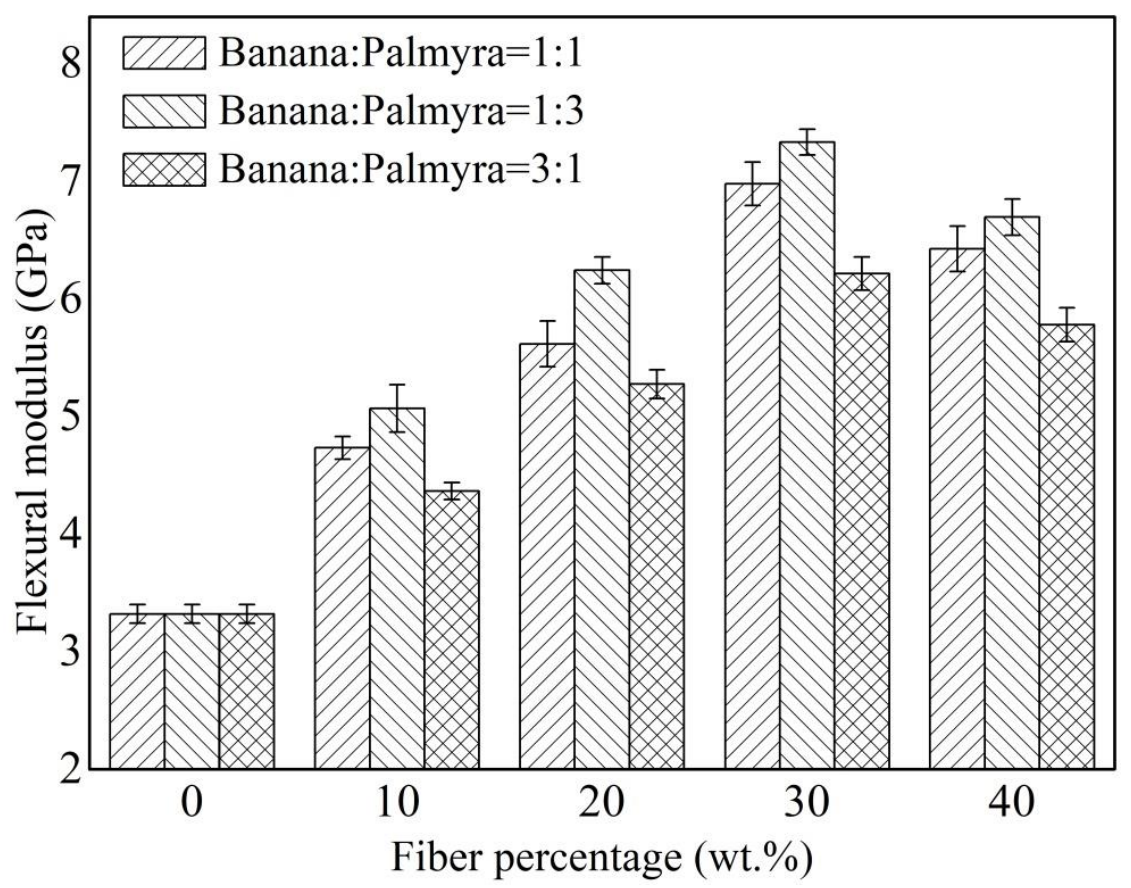

Fig. 7 Flexural modulus comparison of different hybrid composite materials 


\subsection{Impact Energy}

The impact energy of composites governed by the many factors such as fiber breakage, inter-layer delamination, reinforcement and matrix debonding and matrix fracture. The influence of fiber percentage and weight ratio on the charpy impact energy of hybrid composites is analyzed and the results are shown in Fig. 8.

The impact energy of pure epoxy resin is $1.05 \mathrm{~J}$. The impact energy increases as a result of fiber percentage increases because of the increase in fiber breakage and fiber pull out. Based on the Figure, it was perceived that the composite with of banana and jute fiber as 1:3 has higher impact strength than the other two weight ratios. The percentage improvement between the pure epoxy to incorporating fiber percentage of $40 \mathrm{wt}$. \% hybrid composites are $160 \%$, $148 \%$, and $176 \%$ with weight ratio of banana and palmyra reinforcement as 1:1, 1:3, and 3:1, respectively. Similarly, various researchers [17] reported that impact energy of natural reinforced polymer composites increased as fiber weight percentage increased.

\subsection{Micro Hardness}

The micro-hardness of the hybrid composites was investigated by applying compression stress on the combination of matrix phase and reinforcement phase together. The micro hardness of the banana and palmyra fiber reinforced hybrid composites are calculated for the various fiber percentages and weight ratios and the resulting plots are shown in Fig. 9. It can be seen that micro hardness is increases with an increase in fiber percentage up to $40 \mathrm{wt}$. \% for all the weight ratios of composite samples. The micro hardness of the neat epoxy is found be $25.1 \mathrm{HV}$. At maximum fiber percentage, the micro hardness is observed that $39.1 \mathrm{Hv}, 42.3$ $\mathrm{Hv}$ and $36.9 \mathrm{Hv}$ with the corresponding weight ratio of banana and palmyra reinforcement as $1: 1,1: 3$, and $3: 1$. The results designated that the composites with weight ratio of banana and palmyra as 1:3 shown the superior micro-hardness values compared 1:1 and 3:1 weight ratios of composites.

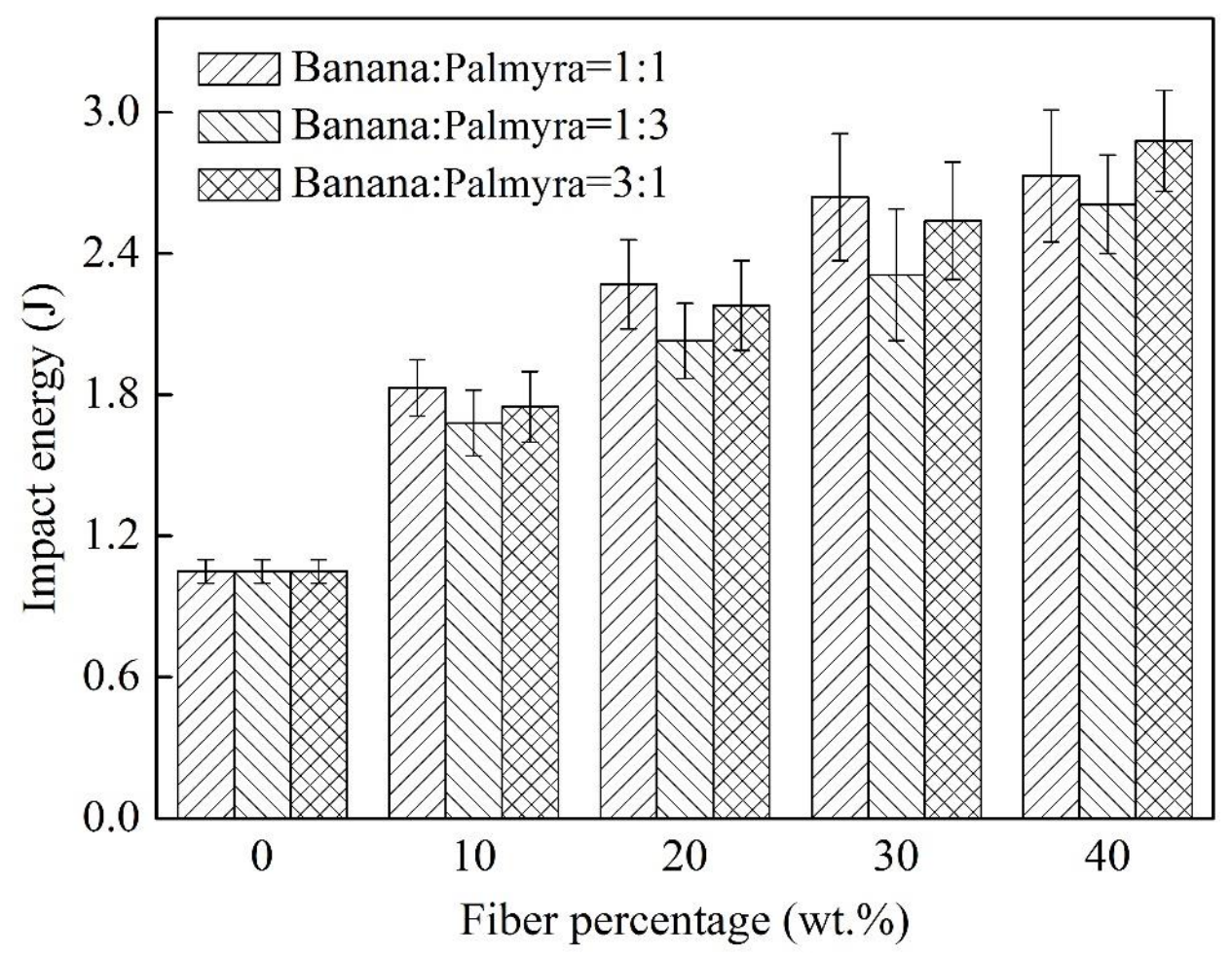

Fig. 8 Impact energy comparison of different hybrid composite materials 


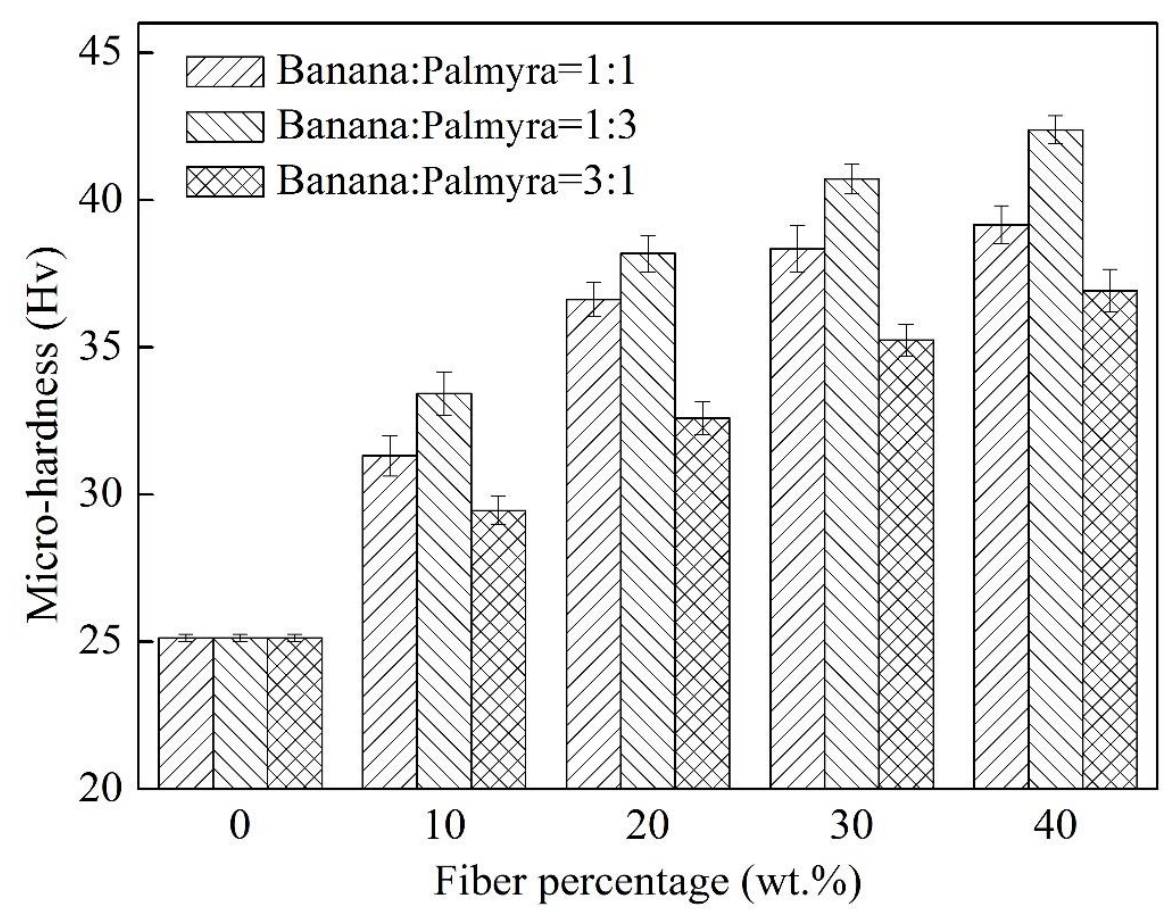

Fig. 9 Micro hardness comparison of different hybrid composite materials

\subsection{Interfacial Analysis using Scanning Electron Microscope}

In order to study the interfacial bonding at the interfaces, the scanning electron microscope images are taken for the tensile tested specimen at maximum values. Fig. 10 shows the scanning electron microscope image for the neat epoxy and hybrid composites at $30 \mathrm{wt} . \%$ of fiber percentage which subjected to tensile test. The image illustrates the fiber breakage of the banana and palmyra fibers, reinforcement-matrix interaction and fiber pullout characteristics reinforcement. Fig. 10(b) to (d), it is observed that the there is good interfacial bonding between the reinforcement and the matrix at $30 \mathrm{wt} \%$ of fiber percentage that leads to improve the strength properties of hybrid composites. 


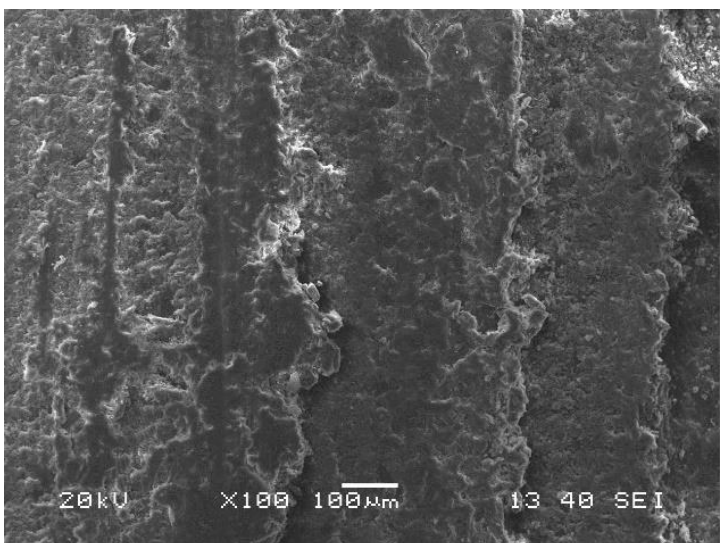

(a)

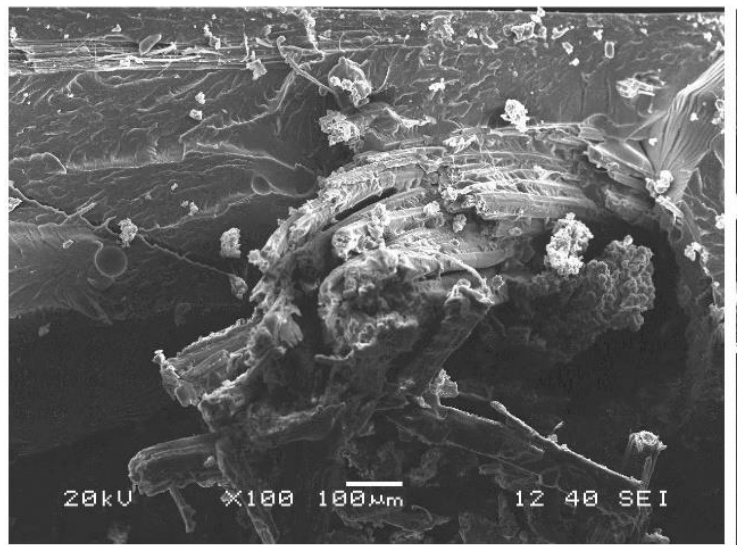

(c)

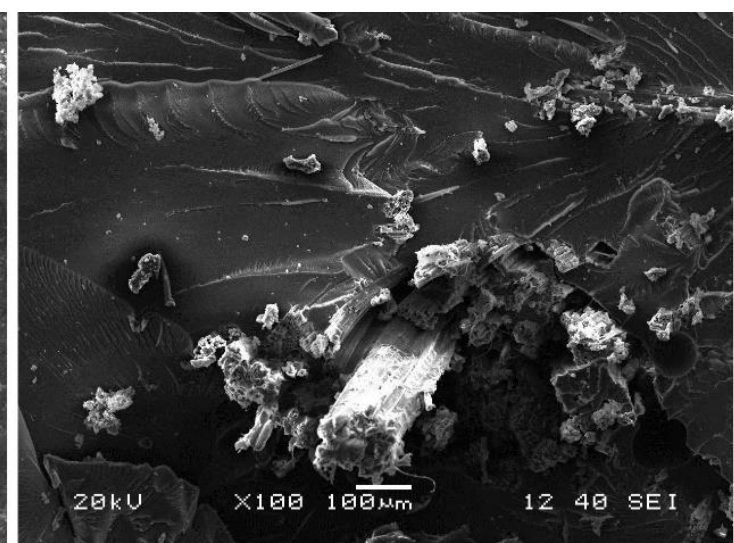

(b)

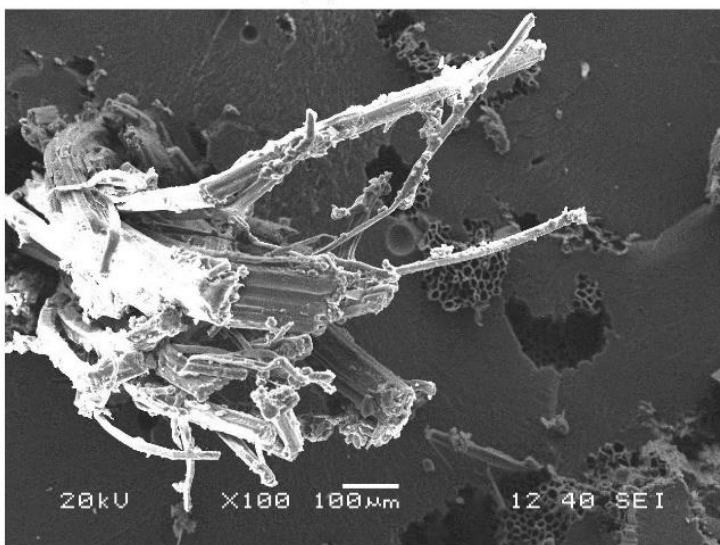

(d)

Fig. 10 Scanning Electron Microscope images of tensile tested neat epoxy and hybrid composites with $30 \mathrm{wt}$. \% of fiber percentage

\section{CONCLUSION}

The influence of fiber percentage and weight ratio on the Interfacial, physical and mechanical properties of banana and palmyra reinforced epoxy composites has been examined. The theoretical and experimental densities of hybrid composite is increases whereas the void percentage increases with increase in the fiber percentage. The minimum water absorption percentage of the hybrid composite is found with weight ratio of banana and palmyra fiber $1: 3$ with the value of $11.51 \%$. The results indicated that the tensile strength and flexural strength of hybrid composites increases with increasing in fiber percentage up to 30 wt. \%, whereas the impact energy and hardness is increases up to $40 \mathrm{wt} . \%$. High tensile strength, hardness and flexural strength is obtained for hybrid composites having weight ratio of banana and palmyra fiber as 1:3, whereas the impact energy is observed in 3:1 weight ratio. The internal cracks and micro structure is detected for the broken surfaces of the tested specimens using scanning electron microscope.

\section{REFERENCES}

[1] Sapuan S. M., Leenie A., Harimi M., Beng Y. K. "Mechanical properties of woven banana fibre reinforced epoxy composites", Materials \& design 27 (8), pp. $689-693$, 2006. DOI: $10.1016 /$ j.matdes.2004.12.016

[2] Mishra V., Biswas S. "Physical and mechanical properties of bi-directional jute fiber epoxy composites", Procedia engineering 51, pp. 561 - 566, 2013. DOI: 10.1016/j.proeng.2013.01.079 
[3] Sathishkumar T. P., Navaneethakrishnan P., Shankar S., Rajasekar R. "Mechanical properties and water absorption of short snake grass fiber reinforced isophthallic polyester composites". Fibers and Polymers 15(9), pp. 1927 - 1934, 2014. DOI: $10.1007 / \mathrm{s} 12221-014-1927-8$

[4] Alamri H., Low I. M. "Mechanical properties and water absorption behaviour of recycled cellulose fibre reinforced epoxy composites", Polymer testing 31 (5), pp. 620 628, 2012. DOI: $10.1016 /$ j.polymertesting.2012.04.002

[5] Venkateshwaran N., ElayaPerumal A. "Mechanical and water absorption properties of woven jute/banana hybrid composites", Fibers and Polymers 13 (7), pp. 907 - 914, 2012. DOI: $10.1007 / \mathrm{s} 12221-012-0907-0$

[6] Devireddy S. B. R., Biswas S. "Physical and mechanical behavior of unidirectional banana/jute fiber reinforced epoxy based hybrid composites", Polymer composites 38 (7), pp. 1396 - 1403, 2017. DOI: 10.1002/pc.23706

[7] Boopalan M., Niranjanaa M., Umapathy M. J. "Study on the mechanical properties and thermal properties of jute and banana fiber reinforced epoxy hybrid composites", Composites Part B: Engineering 51, pp. $54-57$, 2013. DOI: 10.1016/j.compositesb.2013.02.033

[8] Arthanarieswaran V. P., Kumaravel A., Kathirselvam M. "Evaluation of mechanical properties of banana and sisal fiber reinforced epoxy composites: Influence of glass fiber hybridization", Materials \& Design 64, pp. $194 \quad$ - 202, 2014. DOI: 10.1016/j.matdes.2014.07.058

[9] Srinivasan V. S., Boopathy S. R., Sangeetha D., Ramnath B. V. "Evaluation of mechanical and thermal properties of banana-flax based natural fibre composite", Materials \& Design 60, pp. 620 - 627, 2014. DOI: 10.1016/j.matdes.2014.03.014

[10] Saw, S. K., Akhtar K., Yadav N., Singh A. K. "Hybrid composites made from jute/coir fibers: Water absorption, thickness swelling, density, morphology, and mechanical properties", Journal of Natural Fibers 11 (1), pp. 39 - 53, 2014. DOI: $10.1080 / 15440478.2013 .825067$

[11] Lalit, R., Mayank, P., Ankur, K. "Natural fibers and biopolymers characterization: A future potential composite material", Strojnícky časopis - Journal of Mechanical Engineering 68(1), pp. 33 - 50, 2018. DOI: 10.2478/scjme-2018-0004

[12] Bocko, J., Lengvarský, P., Pástor, M. "Estimation of Material Properties of Carbon Nanotubes Using Finite Element Method", Strojnícky časopis - Journal of Mechanical Engineering 69 (2), pp.7 - 14, 2019. DOI: 10.2478/scjme-2019-0014

[13] Narayana, V. L., Rao, L. B., Devireddy, S. B. R. "Effect of fiber percentage and stacking sequence on mechanical performance of unidirectional hemp and palmyra reinforced hybrid composites", Revue des Composites et des Matériaux Avancés - Journal of Composite and Advanced Materials 30 (3 - 4), pp. 153 - 160, 2020. DOI: 10.18280/rcma.303-405

[14] Masoodi R., Pillai K. M. "A study on moisture absorption and swelling in bio-based jute-epoxy composites", Journal of Reinforced Plastics and Composites 31(5), pp. 285 294, 2012. DOI: $10.1177 / 0731684411434654$

[15] Joseph K., Thomas S., Pavithran C., Brahmakumar M. "Tensile properties of short sisal fiber-reinforced polyethylene composites", Journal of Applied Polymer Science 47 (10), pp. 1731 - 1739, 1993. DOI: 10.1002/app.1993.070471003 
[16] Yusoff M. Z. M., Salit M. S., Ismail N., Wirawan R. "Mechanical properties of short random oil palm fibre reinforced epoxy composites", Sains Malaysiana 39 (1), pp. 87 92, 2010. https://www.semanticscholar.org/paper/Mechanical-Properties-of-ShortRandom-Oil-Palm-Yusoff-Salit [Accessed: 11 Nov 2020]

[17] Saw S. K., Datta C. "Thermomechanical properties of jute/bagasse hybrid fibre reinforced epoxy thermoset composites", BioResources 4 (4), pp. 1455 - 1475, 2009. https://ojs.cnr.ncsu.edu/index.php/BioRes/article/view/BioRes_04_4_1455_Saw_Datta_ Thermomechan_Prop_Jute_Bagasse_Composites [Accessed: 11 Nov 2020] 